\title{
Gym Training: To Trained Life; not Only for Fitness, Its Way of Living in Current Scenario to Creating Better Version of Self Through Regular Exercise During Novel Covid-19 Pandemic
}

\author{
Ajeet K Srivastava*1, Shikha Agnihotry ${ }^{2}$ and Pradeep Kumar Shukla ${ }^{3}$ \\ ${ }^{1}$ Research \& Development Division (LuvLap), Universal Corporation Limited, India \\ ${ }^{2}$ Department of Biological Sciences, Sam Higginbottom University of Agriculture, Technology and Sciences, India
}

${ }^{3}$ Department of Biological Sciences, Sam Higginbottom University of Agriculture, Technology and Sciences, Allahabad-211007, India

*Corresponding author: Ajeet K Srivastava,Research \& Development Division (LuvLap), Universal Corporation Limited, Sector-47, Malibu Town, Gurugram-122018, India

ARTICLE INFO

Received: 幽 April 17, 2020

Published: 幽 May 01, 2020

Citation: Ajeet K S, Shikha A. Gym Training: To Trained Life; not Only for Fitness, Its Way of Living in Current Scenario to Creating Better Version of Self Through Regular Exercise During Novel Covid-19 Pandemic. Biomed J Sci \& Tech Res 27(3)-2020. BJSTR. MS.ID.004495.

\begin{abstract}
Lifestyle and its effect on health was a common topic of discussion in the conversation on Health. Physical inactivity and obesity are leading risk factors for global mortality. Many participants voiced concerns related to unhealthy lifestyles and their negative impacts on the health care system. The increasing frequency of obesity related diseases such as diabetes, heart disease, and hypertension are often the product of a nutritionally inadequate diet along with sedentary lifestyle. Many participants emphasized the link between healthy lifestyles, including diet, physical activity and personal habits, and lower rates of chronic disease. There was widespread concern that high levels of obesity in children are associated with poor diets and sedentary lifestyles. Most of our diseases are caused by lifestyle, particularly the consumption of animal products. Chronic obesity, smoking and drug use are voluntary conditions which cost the health system a lot of money. It can be difficult to get people to make positive lifestyle choices. It is important to recognize that there are major differences between obesity and smoking. First, food and activity are essential to life; tobacco is not. There are possible negative consequences of a focus on obesity, such as disordered eating, that should be taken into account.
\end{abstract}

Abbreviations: GCC: Gulf Cooperation Council; CVD: Cardiovascular Disease; PA: Physical Activity

\section{Introduction}

Physical inactivity and obesity are leading risk factors for global mortality [1]. The increase in the global obesity epidemic during the past few decades is substantial. However, there are wide variations in obesity prevalence across countries and populations due to socioeconomic, cultural and transport differences in national and local environments [2]. Industrial countries have witnessed significant technological advancement and automation during the first half of the 20 th century. This was paralleled by decreases in food energy supply that helped in preserving low obesity prevalence. However, in the 1970s-1980s, an energy balance turning point seems to have occurred in many high-income countries [3], followed by a number of middle-income and low-income countries who have joined the global surge in obesity prevalence in adults and children [4,5]. It appears that the most obvious environmental precondition for a population to develop obesity is sufficient wealth and economic prosperity [5]. Since the discovery of oil in the Arabian Gulf region in the 1960s, the Gulf Cooperation Council (GCC) countries that comprise Bahrain, Kuwait, Qatar, Oman, Saudi Arabia and the United Arab Emirates (UAE) have experienced continued growth in population, per capita income and wealth. The UAE and Qatar in particular have grown the fastest in terms 
of population, per capita income and wealth [6]. With this growth the Qatari population has witnessed significant lifestyle changes due to rapid urbanisation, the dominance of personal transport, the introduction of labour-saving devices, the availability of high-fat and dense-caloric foods, increased reliance on telecommunication technology, as well as decreased occupational-work demands $[7,8]$.

These lifestyle changes have had a considerable impact on reducing the physical requirements of daily life and have encouraged sedentary lifestyles. This lifestyle transformation is thought to be greatly responsible for the significant increase in non-communicable diseases, such as cardiovascular disease (CVD), cancer and diabetes mellitus type II in Qatar [9]. Diabetes and CVD have become the leading causes of morbidity and mortality over the past two decades in Qatar [10]. The most important risk factors of non-communicable diseases in the Arabian Gulf countries include high blood pressure, high concentrations of cholesterol in the blood, inadequate intake of fruit and vegetables, being overweight or obesity, physical inactivity and tobacco use [9]. Five of these risks are closely related to inappropriate diet and physical inactivity. In the GCC countries, alarming levels of physical inactivity have been reported, as well as poor dietary practices, predisposing them to health problems [11-13]. To date, limited attempts have been made to examine the interrelationship of these risk factors within young adults. However, directional relationships have been identified in several studies. For example, previous research has demonstrated positive correlations between:

1) Sugar-sweetened beverage consumption and poor dietary habits [14];

2) Skipping breakfast, lower nutritional status and increasing the risk of cardio-vascular disease [15]; and

3) Low fruit and vegetable intake and low physical activity (PA) [16]. Consequently, whilst these studies have tended to focus on the significance of one unhealthy behaviour in isolation, research has shown that health behaviours often coexist with clear evidence of clustering [16-26].

\section{Different Class of Weight Reduction}

\section{Abs Crunch}

Side Plank: When in plank position, rotate on to one side, holding your weight on one forearm, with legs straight and feet stacked on top of each other. Lift the other arm. Push your hip to the ceiling to maintain alignment. on other side. Control your breathing (Figure 1).

Figure 1: Basic
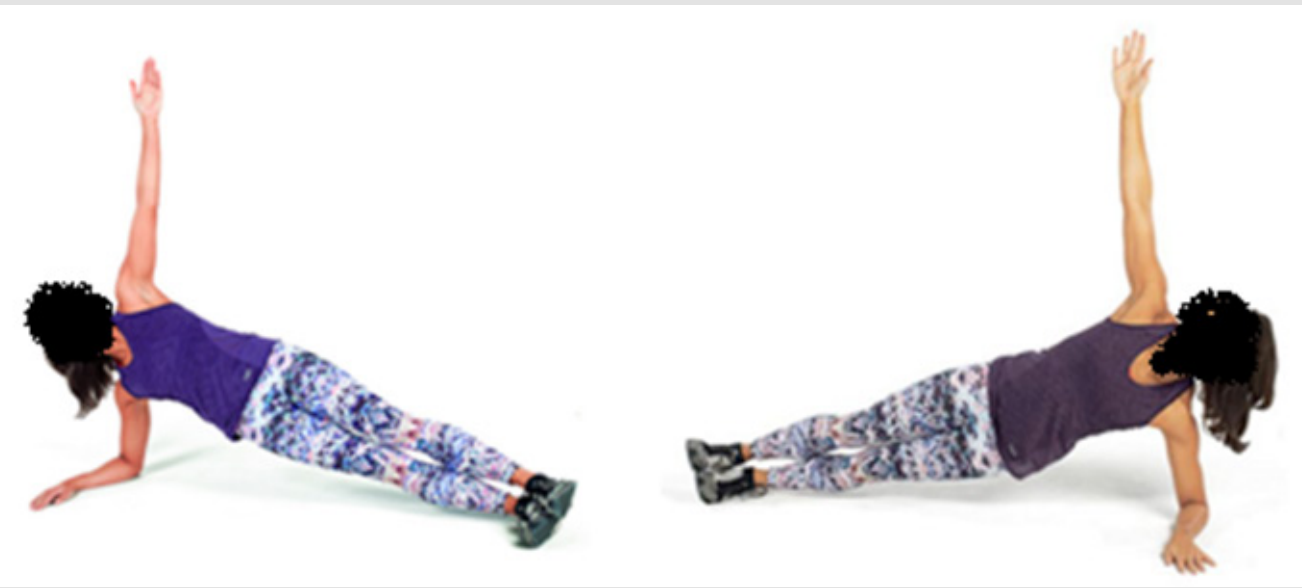

Front Plank: When in plank position, rotate on to one side, holding your weight on both forearm, with legs straight and feet stacked on top of each other. Lift the other arm. Push your hip to the ceiling to maintain alignment. On other side, Control your breathing. Squeeze your core muscles to maintain the position (Figure 2).

Dead Bugs: Lie on your back with knees bent to 90 degrees, arms up. Slowly lower left heel towards floor while extending right arm over head. Slowly return to starting position and repeat on the other side (Figure 3).

Toe Taps: Keeping your body upright, drive your arms in a running motion, while lifting one leg at a time, knee bent. Gently tap each foot on the top of a step. Repeat, alternating as fast as you can (Figure 4).

Jump Squats: Stand with feet slightly wider than shoulderwidth apart, toes pointing forwards. Lower hips and bend knees to 90 degrees, with chest upright. Jump up in the air, land gently on both feet and repeat. Repeat toe taps, as before (Figure 5).

Inchworm: From a standing position, bend over so your hands are on the floor in front of you (bend your knees if you need to). Slowly inch hands forward one by one until you can go no farther. Then inch them closer to your body until you're back in starting position. Repeat toe taps, as before (Figure 6). 


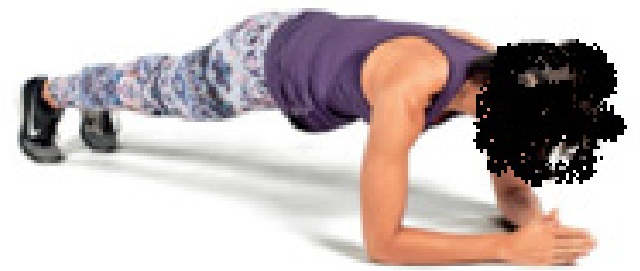

Figure 2: Basic

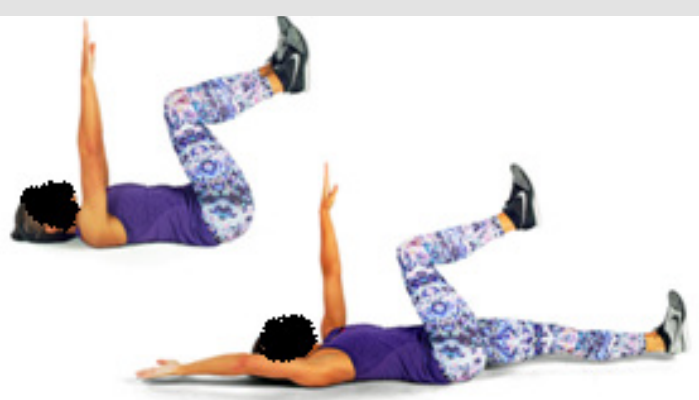

Figure 3: Basic
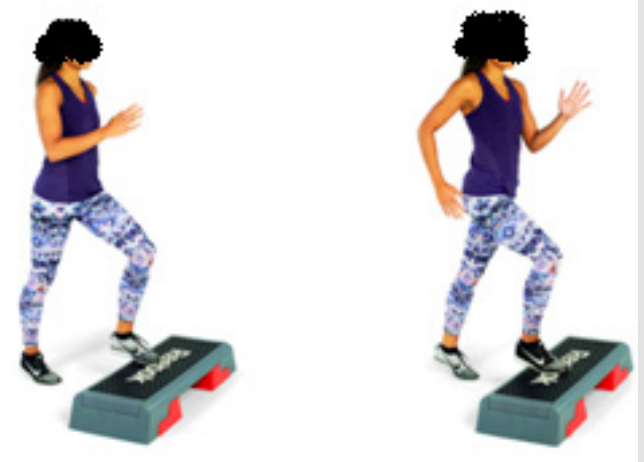

Figure 4: Basic

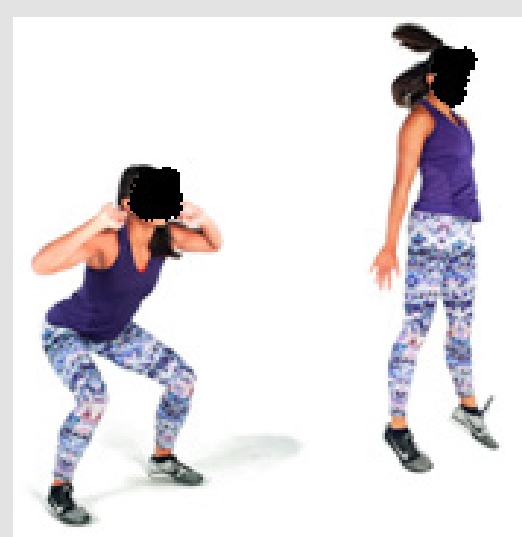

Figure 5: Basic

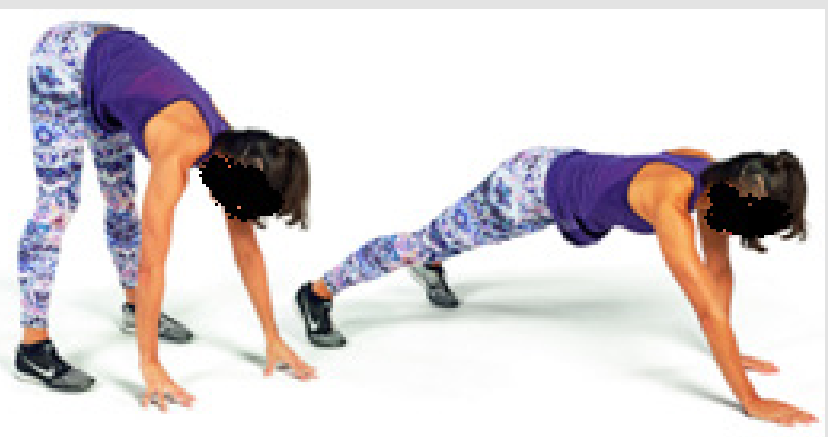

Figure 6: Basic

Modified Press-Up: In a kneeling push-up position, make sure you keep head, neck and back in a straight line. Slowly bend elbows until your chest touches the floor. Pause before pushing up to starting position. Do not stick your bum out. Repeat toe taps, as before (Figure 7).

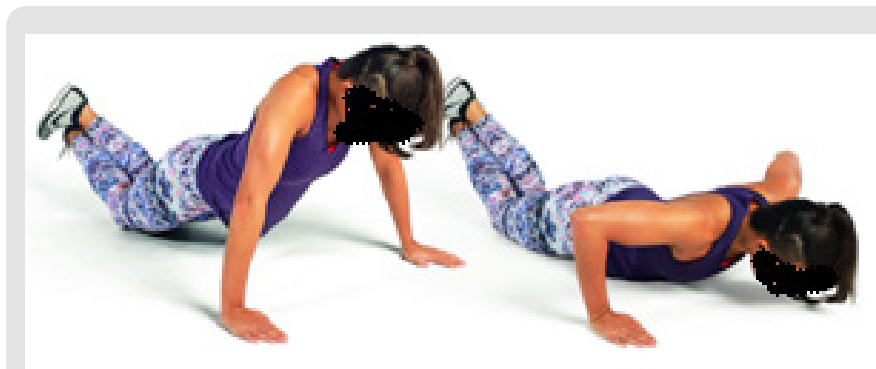

Figure 7: Basic

Burpees: Crouch in a tuck position with hands on the floor. Extend legs out into a plank, balancing weight on palms and toes. Return to tuck position before driving through toes and jumping up. Repeat as many times as you can. Repeat toe taps, as before (Figure 8).

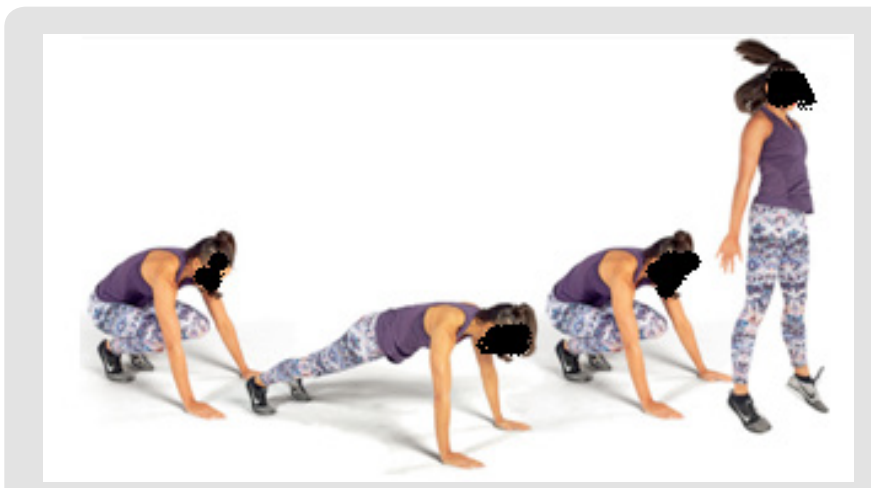

Figure 8: Basic

Bicycle Crunch: Lie on your back with knees bent to 90 degrees and hands by your ears. Slowly extend left heel towards the floor while reaching left elbow across to right knee. Repeat on opposite side (Figure 9).

Mountain Climber: Starting in plank position, lift left toe off floor, bring left knee towards chest and gently tap floor with toe. 
Return to plank and repeat on right. Alternate as fast as you can. Repeat toe taps, as before (Figure 10).

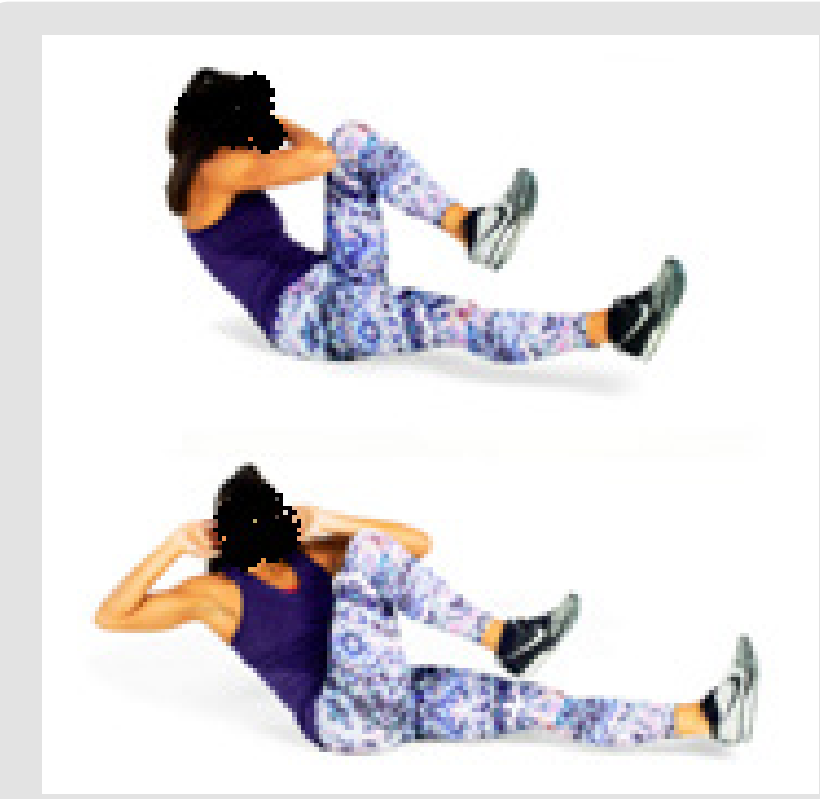

Figure 9: Basic

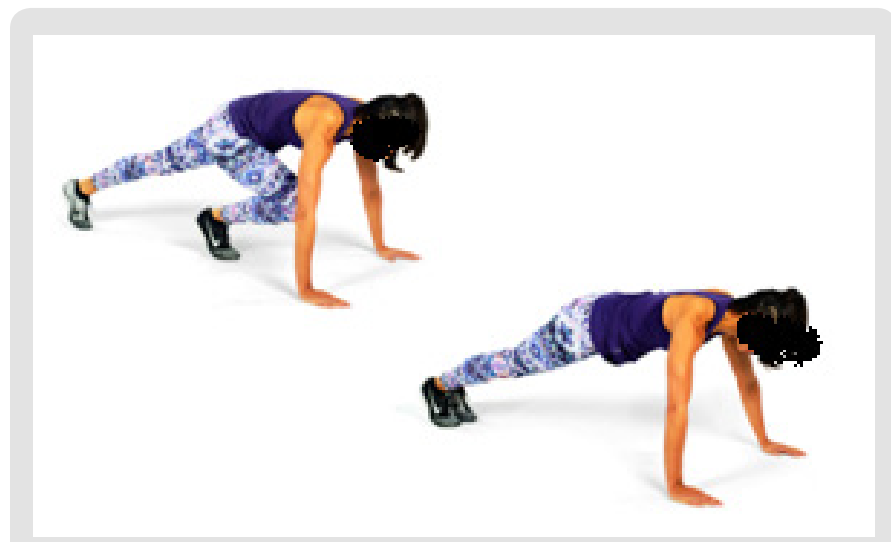

Figure 10 : Basic
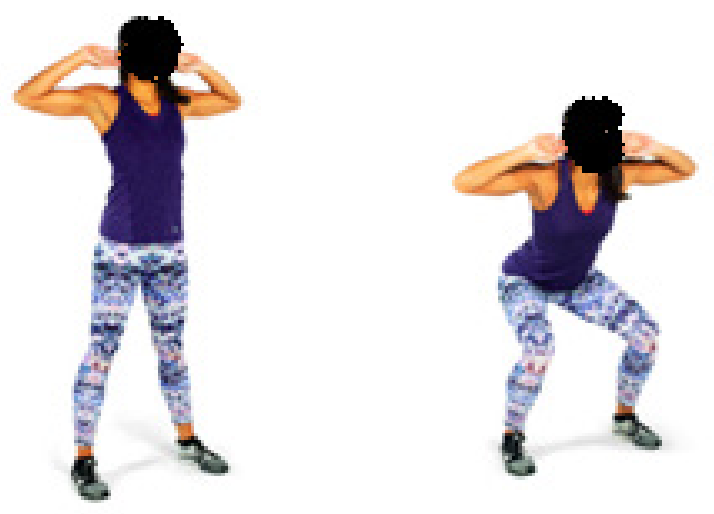

Figure 8: Basic

Back Squat: Stand with feet slightly wider than shoulder-width apart, and straight. Lower hips and bend knees to 90 degrees, keeping chest upright. Pause, then return to standing position. Repeat toe taps, as before (Figure 11).

Plank Spiderman: Start in plank position, but with arms bent. Lift your left toe and raise your left knee out towards your left elbow. Repeat on the right side, then alternate sides in a controlled motion. Repeat toe taps, as before (Figure 12).

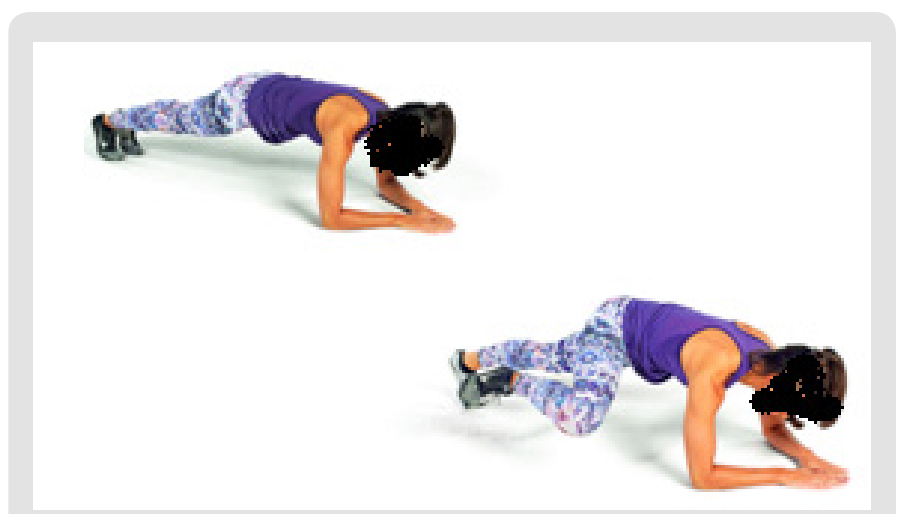

Figure 12: Basic

\section{Stretching}

Neck: Stand in a relaxed position. Ease your head down towards one side, using your hand to pull it down gently. Repeat on the other side (Figure 13).

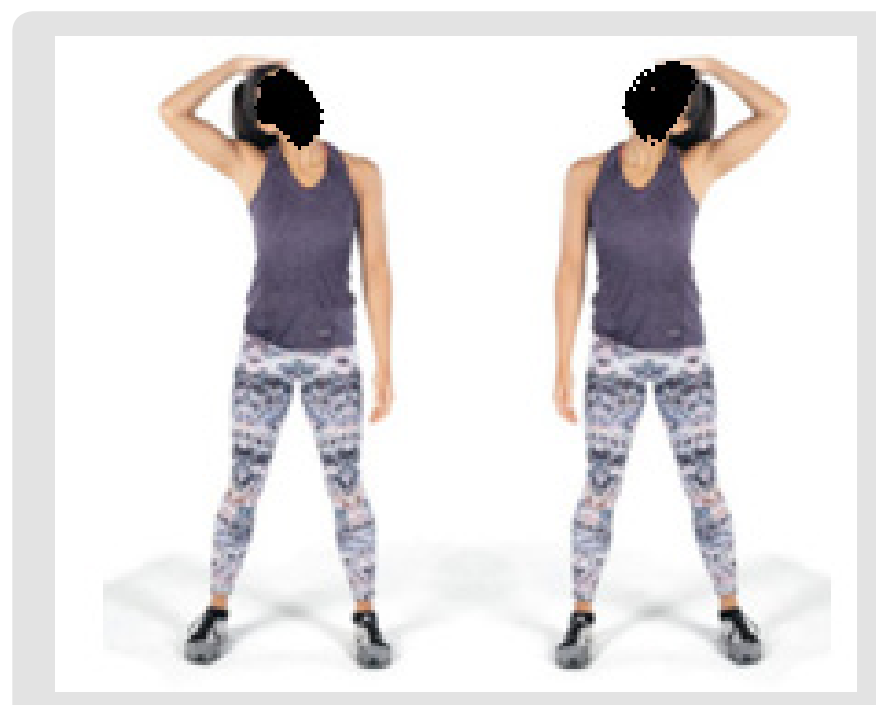

Figure 13: Basic

Shoulders: Stand in a relaxed position with feet shoulderwidth apart. Put one arm out straight and pull it across your body with the other hand. Repeat on the other side (Figure 14).

Overhead Triceps: Stand in a relaxed position. Raise one arm, elbow bent, with your hand facing down your back. Use your other hand to stretch your tricep. Repeat on the other side (Figure 15).

Calf: Step forward into a gentle lunge, keeping back leg straight. Press against a wall to deepen the stretch (Figure 16). 

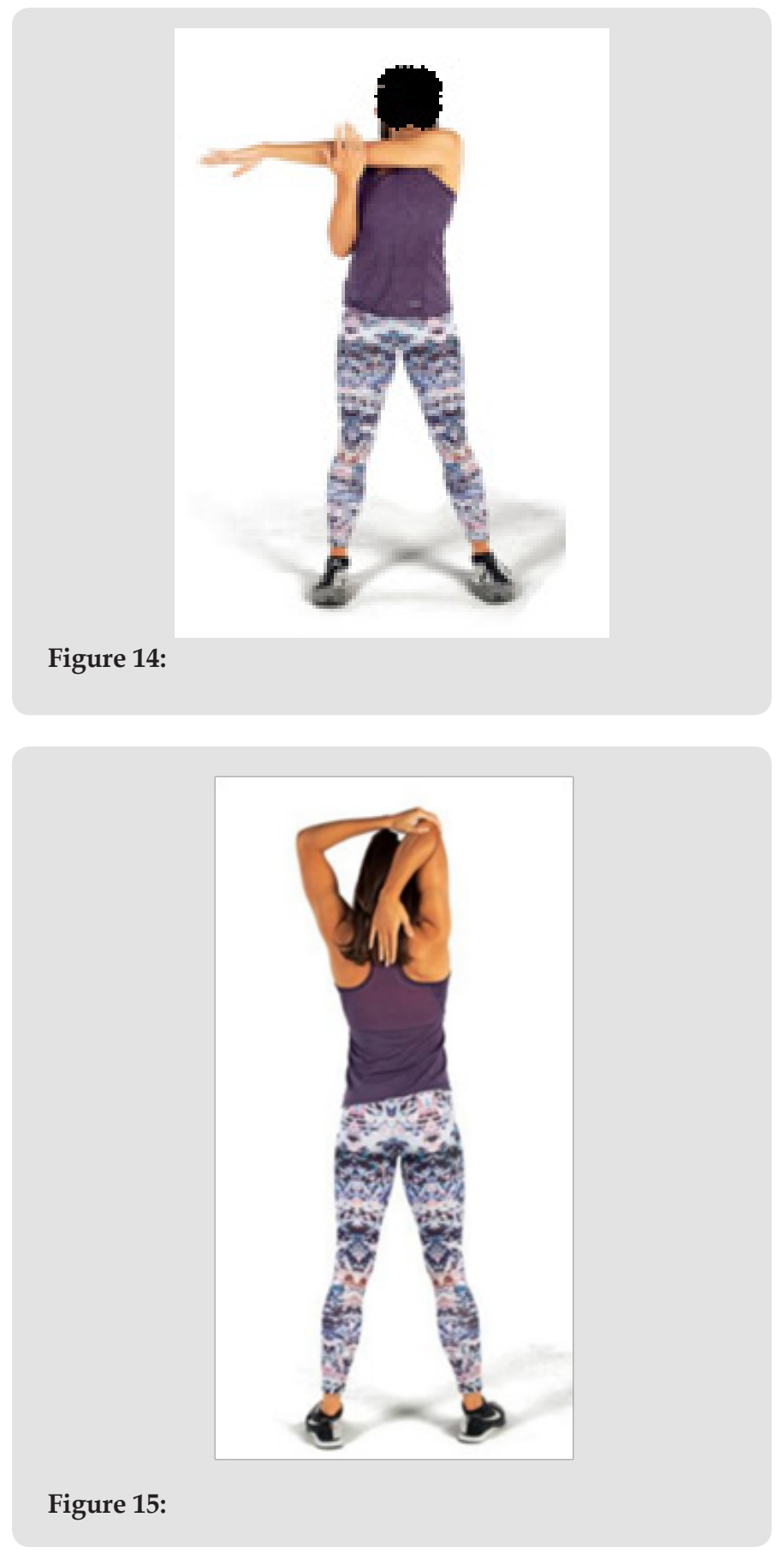

Butterfly: Sit on the floor and bend both knees, keeping feet together and back straight. Use your elbows to deepen the stretch (Figure 17).

Hamstring: Sit on the floor and put one leg straight out in front of you, with the other leg bent. Lean forward and reach as far as you can. Repeat on the other side (Figure 18).

Lower Back: Lie on your back with legs out straight. Raise one knee, pulling it towards your chest. Hold, then repeat with the other leg (Figure 19).

Glute Stretch: Lie on your back with your knees bent. Put your right foot on to your left knee, so that your knee is out to one side.
Pull your left leg in towards you. Hold, then repeat on the other side (Figure 20).

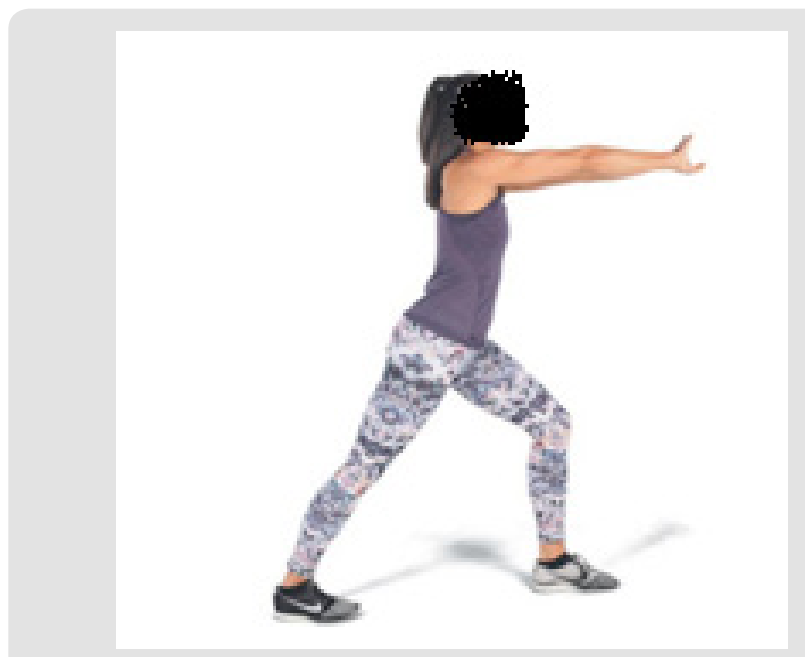

Figure 16:

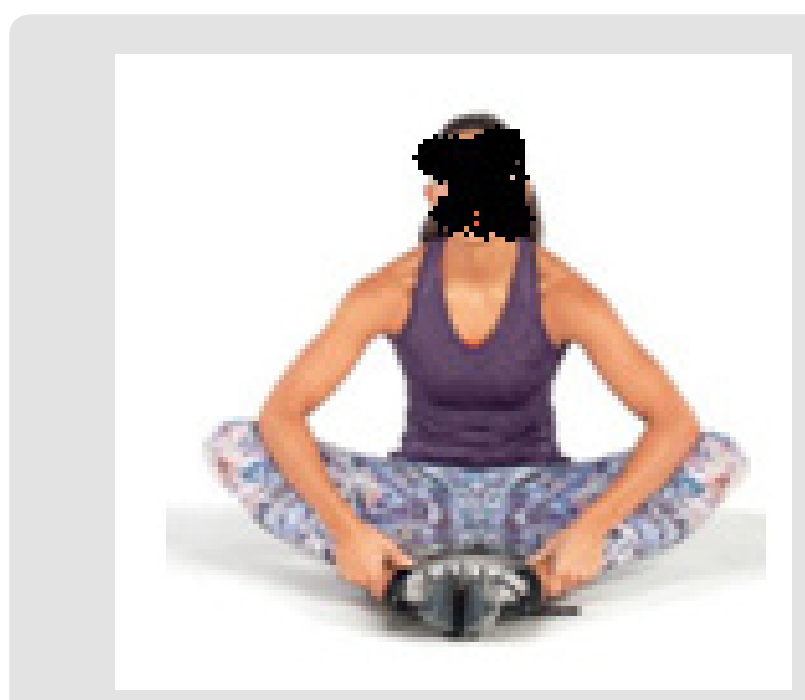

Figure 17:

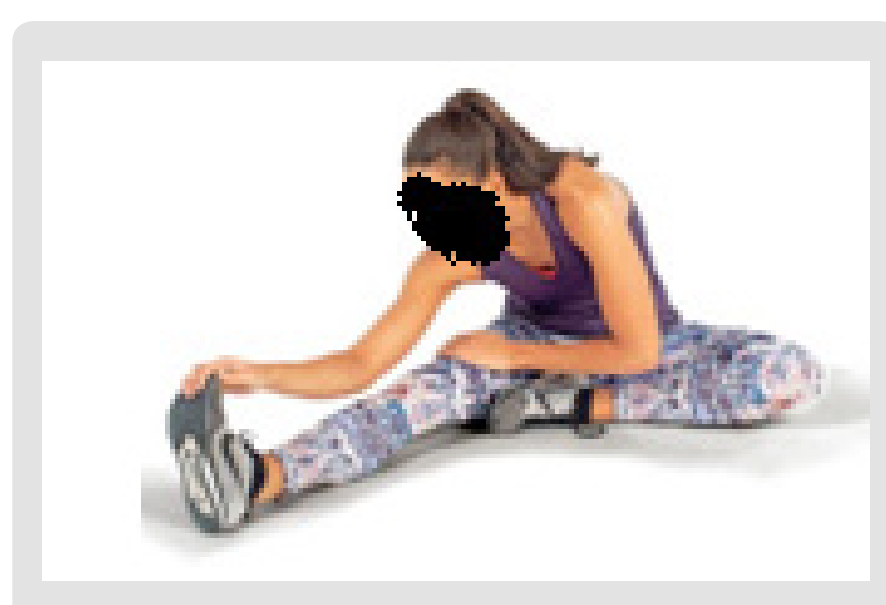

Figure 18: Basic 


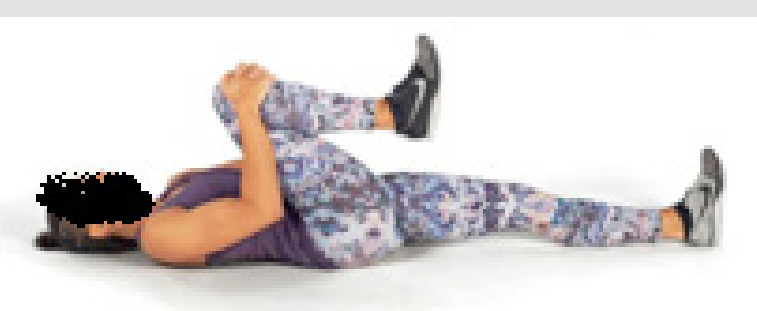

Figure 19: Basic

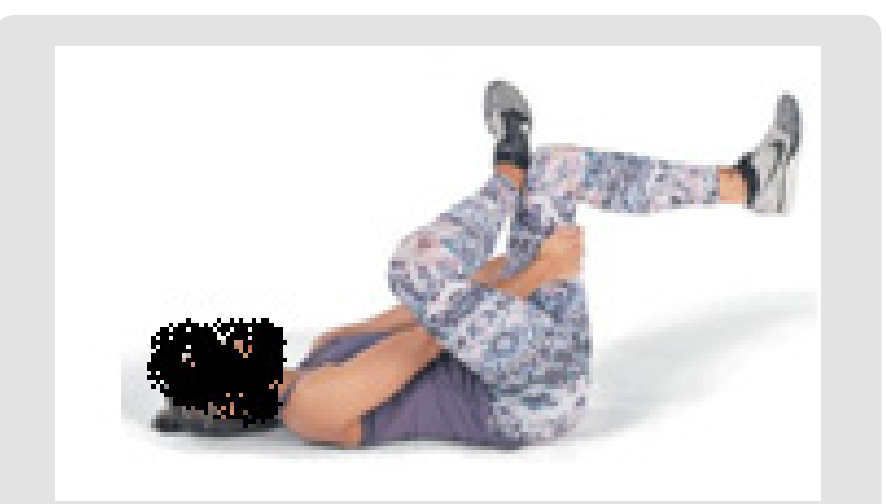

Figure 20: Basic

Cat Stretch: Start on all fours, looking straight ahead. Sink your spine and stick out your bottom, arching your back. Then invert the stretch, curving your back, with your head lowered (Figure 21).
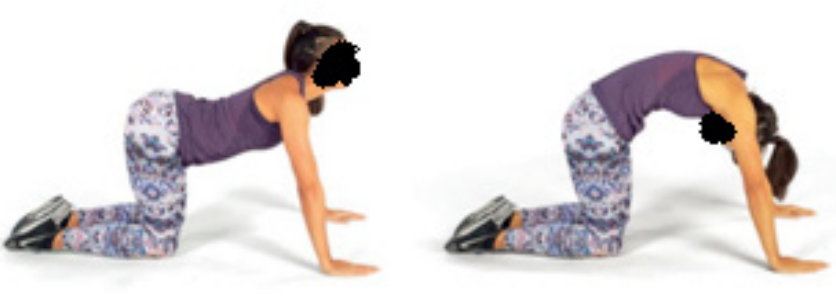

Figure 21: Basic

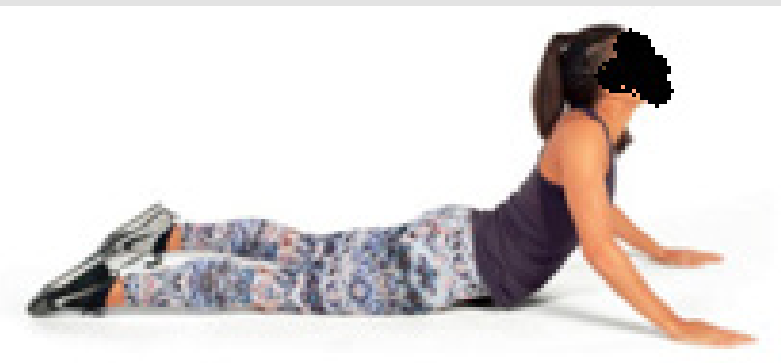

Figure 21: Basic
Cobra: Lie face down with arms bent on the ground. Push up with them to lift your torso and gently arch your back (Figure 22).

\section{Instrument Based Cardio +Abdominal}

\section{Treadmill}

A treadmill is a device generally for walking or running or climbing while staying in the same place.

\section{Cross Trainer}

An elliptical trainer or cross-trainer (also called an $\mathrm{X}$-trainer) is a stationary exercise machine used to simulate stair climbing, walking, or running without causing excessive pressure to the joints, hence decreasing the risk of impact injuries.

\section{Acknowledgement}

I heartily acknowledged of our team. All photos which indicated position and steps are highly recognize the worth of source image.

\section{References}

1. (2004) Department of Health; Physical Activity; Health Improvement and Protection At Least Five a Week: Evidence on the Impact of Physical Activity and its Relationship to Health; Crown, London, UK.

2. Swinburn BA, Sacks G, Hall KD, Mc Pherson K, Finegood DT, et al. (2011) The global obesity pandemic: Shaped by global drivers and local environments. Lancet 378(9793): 804-814.

3. Sassi F, Devaux M, Cecchini M, Rusticalli E (2009) The Obesity Epidemic: Analysis of Past and Projected Future Trends in Selected OECD Countries; Organisation for Economic Co-operation and Development (OECD); Directorate for Employment; Labour and Social Affairs; Health Committee: Paris France.

4. Finucane MM, Stevens GA, Cowan MJ, Danaei G, Lin JK, et al. (2011) National regional and global trends in body-mass index since 1980: Systematic analysis of health examination surveys and epidemiological studies with 960 country-years and 91 million participants. Lancet 377(9765): 557-567.

5. Lobstein T, Leach R (2007) Tackling Obesities: Future ChoicesInternational Comparisons of Obesity Trends Determinants and Responses-Evidence Review; Government Office for Science: London, UK.

6. Ng SW, Zaghloulm S, Ali HI, Harrison G, Popkin BM (2011) The prevalence and trends of overweight obesity and nutrition-related noncommunicable diseases in the Arabian Gulf States. Obes Rev 12:1-13. Int J Environ Res Public Health 12(1): 4392.

7. Al Nuaim AA, Al Nakeeb Y, Lyons M, Al Hazzaa H, Nevill A, et al. (2012) The prevalence of physical activity and sedentary behaviours relative to obesity among adolescents from Al-Ahsa Saudi Arabia: Rural vs urban variations. J Nutr MeTable.

8. Al Nakeeb Y, Dodd L, Lyons M, Collins P, Al Nuaim AA (2014) A cluster analysis of lifestyle and health habits of youth from two geographically and culturally diverse countries. Open J Prev Med 4(4): 193-203.

9. (2014) World Health Organization (WHO) World Health Statistics-2014; World Health Organization (WHO) Press: Geneva Switzerland.

10. Bener A, Al-Suwaidi J, Al-Jaber K, Al-Marri S, Elbagi IEA (2004) Epidemiology of hypertension and its associated risk factors in the Qatari population. J Hum Hyperten 18(7): 529-530.

11. Al-Hazzaa H (2004) Prevalence of physical inactivity in Saudi Arabia: A brief review. East Mediter Health J 10(4-5): 663-670. 
12. Al-Nakeeb Y, Lyons M, Collins P, Al-Nuaim A, Al-Hazzaa H, et al. (2012) Obesity physical activity and sedentary behavior amongst British and Saudi youth: A cross-cultural study. Intl J Environ Res Public Health 9(4) 1409-1506

13. Al-Nozha MM, Al-Hazzaa HM, Arafah M, Al-Khadra A, Al-Mazrou YY, et al. (2007) Prevalence of physical activity and inactivity among Saudis aged 30-70 years: Population-based cross-sectional study. Saudi Med J 28(4): 559-568.

14. Al Qauhiz NM (2010) Obesity among Saudi female university students: Dietary habits and health behaviours. J Egypt Public Health Assoc 85(12): 45-59.

15. Washi SA, Ageib MB (2010) Poor diet quality and food habits are related to impaired nutritional status in 13- to 18-year-old adolescents in Jeddah. Nutr Res 30(8): 527-534.

16. Dodd L, Al Nakeeb Y, Nevill A, Forshaw MJ (2010) Lifestyle risk factors of students: A cluster analytical approach. Prev Med 51(1): 73-77.

17. Adams T, Colner W (2008) The association of multiple risk factors with fruit and vegetable intake among a nationwide sample of college students. J Am Coll Health 56(4): 455-461.

18. Chiolero A, Wietlisbach V, Ruffieux C, Paccaud F, Cornuz J (2006) Clustering of risk behaviors with cigarette consumption: A populationbased survey. Prev Med 42(5): 348-353.

19. Chou K (2008) The prevalence and clustering of four major lifestyle risk factors in Hong Kong Chinese older adults. J Aging Health 20(7): 788803.

ISSN: 2574-1241

DOI: $10.26717 /$ BJSTR.2020.27.004495

Ajeet K Srivastava. Biomed J Sci \& Tech Res

(C) This work is licensed under Creative

Submission Link: https://biomedres.us/submit-manuscript.php
20. De Vries H, Kremers S, Smeets T, Reubsaet A (2008) Clustering of diet physical activity and smoking and a general willingness to change. Psychol Health 23(3): 265-278.

21. Keller S, Maddock JE, Hannöver W, Thyrian JR, Basler HD (2008) Multiple health risk behaviors in German first year university students. Prev Med 46(3): 189-195.

22. Poortinga $W$ (2007) The prevalence and clustering of four major lifestyle risk factors in an English adult population. Prev Med 44(2): 124-128.

23. Pronk NP, Anderson LH, Crain AL, Martinson BC, O'Connor PJ, et al. (2015) Meeting recommendations for multiple healthy lifestyle factors Prevalence Int J Environ Res Public Health 12: 4393. clustering and predictors among adolescent adult and senior health plan members. Am J Prev Med 200427 25-33.

24. Reedy J, Haines PS, Campbell MK (2005) The influence of health behavior clusters on dietary change Prev Med 41(1): 268-275.

25. Sanchez A, Norman GJ, Sallis JF, Calfas KJ, Cella J, et al. (2007) Patterns and correlates of physical activity and nutrition behaviors in adolescents. Am J Prev Med 32(2): 124-130.

26. Theodorakis Y, Papaioannou A, Hatzigeorgiadis A, Papadimitriou E (2005) Patterns of health-related behaviors among Hellenic students. Hellenic J Psychol 2: 225-242.

\begin{tabular}{ll} 
BIOMEDICAL & Assets of Publishing with us \\
RESEARCHES & - Global archiving of articles \\
& - Immediate, unrestricted online access \\
\hline
\end{tabular}

